\title{
Многослойные фоточувствительные структуры на основе пористого кремния и соединений редкоземельных элементов: исследования спектральных характеристик
}

\author{
(C) Н.Ю. Кирсанов ${ }^{1}$, Н.В. Латухина ${ }^{1}$, Д.А. Лизункова ${ }^{1}$, \\ Г.А. Рогожина ${ }^{1}$, М.В. Степихова ${ }^{2}$ \\ ${ }^{1}$ Самарский национальный исследовательский университет им. академика С.П. Королева \\ 443011 Самара, Россия \\ ${ }^{2}$ Институт фризики микроструктур Российской академии наук, \\ 603950 Нижний Новгород, Россия \\ E-mail: natalat@yandex.ru
}

(Получена 26 июля 2016 г. Принята к печати 12 сентября 2016 г.)

Исследованы спектральные характеристики коэффициента зеркального отражения, фоточувствительности и фотолюминесценции многослойных структур на основе пористого кремния с ионами редкоземельных элементов. Показано, что фоточувствительность таких структур в диапазоне длин волн $0.4-1.0$ мкм повышена по сравнению со структурами без редкоземельных элементов. Структуры с ионами $\mathrm{Er}^{3+}$ проявляют люминесцентные свойства при комнатной температуре в спектральном диапазоне от 1.1 до 1.7 мкм. Спектр фотолюминесценции эрбиевой примеси представлен тонкой структурой линий, отражающих структуру расщепления мультиплета ${ }^{4} I_{15 / 2}$ иона $\mathrm{Er}^{3+}$. Показано, что структуры с пористым слоем на рабочей поверхности имеют значительно более низкий коэффициент отражения во всем измеряемом спектральном диапазоне $0.2-1.0$ мкм.

DOI: 10.21883/FTP.2017.03.44209.8377

\section{1. Введение}

Многослойные структуры на основе пористого кремния и соединений редкоземельных элементов (РЗЭ) могут быть основой эффективных фотопреобразователей на кремниевой подложке. Экспериментально доказано, что кремниевые солнечные элементы, не уступающие по эффективности преобразования энергии наногетероструктурам на основе $\mathrm{A}^{\mathrm{III}} \mathrm{B}^{\mathrm{V}}$, могут быть созданы на основе многослойных структур на кремниевой подложке, в составе которых есть материалы с различной шириной запрещенной зоны, а также переизлучающие слои с ионами РЗЭ. Такая стратегия, применяемая в кремниевых солнечных элементах третьего поколения, позволяет поднять их КПД до 40\% и выше [1].

В данной работе в фоточувствительных структурах в качестве слоев широкозонного материала использовались слои нанокристаллического пористого кремния и слои пористого карбида кремния. Кроме них в структурах присутствовали слои фторида диспрозия в качестве просветляющего и пассивирующего покрытия. Исследовались спектральные характеристики коэффициента зеркального отражения рабочей поверхности структур и их фоточувствительности для разных типов поверхности. С целью расширения спектрального диапазона чувствительности и исследования возможностей использования в этих материалах эффектов переизлучения в работе рассматривались структуры с пористым слоем, содержащим ионы эрбия [2].

\section{2. Методика эксперимента}

\section{1. Методика изготовления}

Для получения пористого слоя (por-Si) пластины кремния подвергались электрохимическому травлению, в качестве травителя использовались водно-спиртовые смеси плавиковой кислоты. Использовались пластины монокристаллического кремния с различным микрорельефом поверхности: шлифованные, полированные и текстурированные, т. е. заполненные правильными четырехгранными пирамидами со стороной основания от 2 до 5 мкм. Поверхность шлифованных и полированных образцов была ориентирована по кристаллографической плоскости (111), текстурированных - по плоскости (100). Затравками порообразования на шлифованной и текстурированной поверхностях служат углубления микрорельефа, где напряженность электрического поля максимальна, поэтому пористый слой на таких поверхностях образуется локально в местах соприкосновения пирамид [3]. На рис. 1 приведены изображения поперечного скола $(a)$ и поверхности $(b)$ текстурированного образца с пористым слоем. Рис. 1, $c$ представляет собой схематичное изображение образца. Толщина пористого слоя регулировалась временем травления и плотностью тока. В образцах фоточувствительных структур $p-n$-переход создавался диффузией фосфора для получения стороны $n$-типа проводимости, а для получения слоя $p$-типа наносилась пленка из борного диффузанта. Контакты на стороне $n$-типа создавались термическим испарением в вакууме металлов в последовательности 
$a$
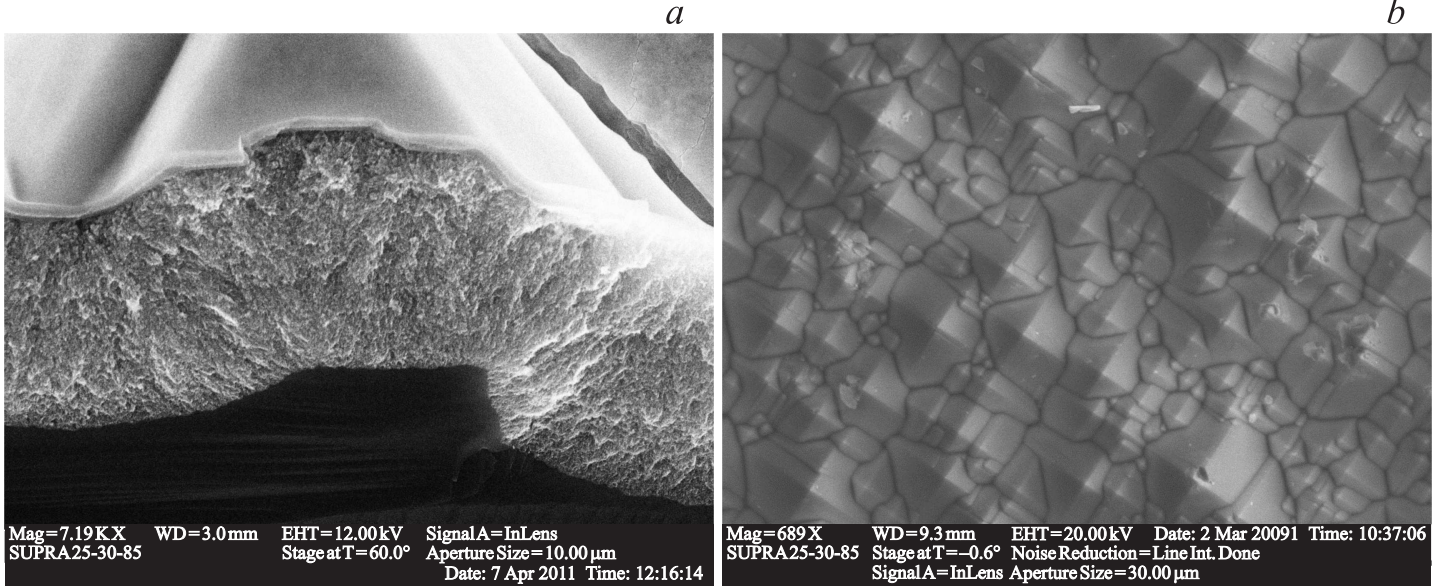

$\longmapsto 2 \mu \mathrm{m}$

$\longmapsto 20 \mu \mathrm{m}$

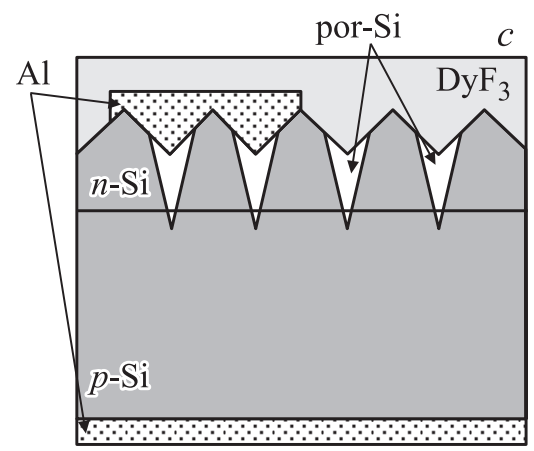

Рис. 1. РЭМ-изображения поперечного скола образца с пористым слоем, образованным на текстурированной поверхности: $a-$ вид сбоку, $b-$ вид сверху. $c$ - схематичное изображение поперечного скола многослойной структуры с пористым слоем, оптическим покрытием и алюминиевыми контактами.

титан-палладий-серебро, после чего производилась фотолитография контактного рисунка в виде гребенки. Завершающим этапом было нанесение в вакууме покрытий из фторида диспрозия поверх контактной сетки.

Пористый слой, насыщенный ионами эрбия, создавался выдержкой образцов в водном растворе азотнокислого или сернокислого эрбия с последующим отжигом на воздухе при $800^{\circ} \mathrm{C}$ в течение 1 ч.

Карбидизация образцов, приводящая к образованию слоя пористого карбида кремния и формированию гетероструктур $\mathrm{SiC} / \mathrm{Si}$, проводилась методом газотранспортной эндотаксии в потоке водорода в вертикальном реакторе с холодными стенками с использованием графитового контейнера [3].

\section{2. Методика исследований}

Были проведены исследования спектральных характеристик фоточувствительности и фотолюминесценции (ФЛ) образцов многослойных структур, а также коэффициента зеркального отражения поверхностей разного типа.

Исследование фоточувствительности проводилось для образцов многослойных структур с $p-n$-переходом и покрытиями из фторида диспрозия в диапазоне длин волн 0.4-1.0 мкм на монохроматоре МДР-3. Фоточувствительность $(S)$ определялась с учетом спектра лампы как отношение фототока к мощности падающего излучения.

Исследование фотолюминесценции проводилось для образцов структур, в которых пористый слой содержал ионы эрбия. Измерения спектров проводились в диапазоне от 1.0 до 1.7 мкм при комнатной температуре на фурье-спектрометре BOMEM DA3.36 с разрешением 1 и $4 \mathrm{~cm}^{-1}$ (0.24 и 0.94 нм соответственно). Сигнал ФЛ детектировался германиевым детектором Edinburgh Instruments, модель ЕО-817А, для возбуждения использовался $\mathrm{Nd}$ :YAG-лазер, длина волны возбуждения 532 нм. Во всех случаях интенсивность лазерного возбуждения составляла 200 мВт, размер лазерного пучка $\sim 3$ мм (диаметр).

В качестве тестового образца (образца сравнения) использовалась стандартная подложка кремния марки КДБ-12.

Спектральные зависимости коэффициента зеркального отражения исследовались на спектрофотометре SHIMADZU UV-2450РC в диапазоне длин волн от 0.19 


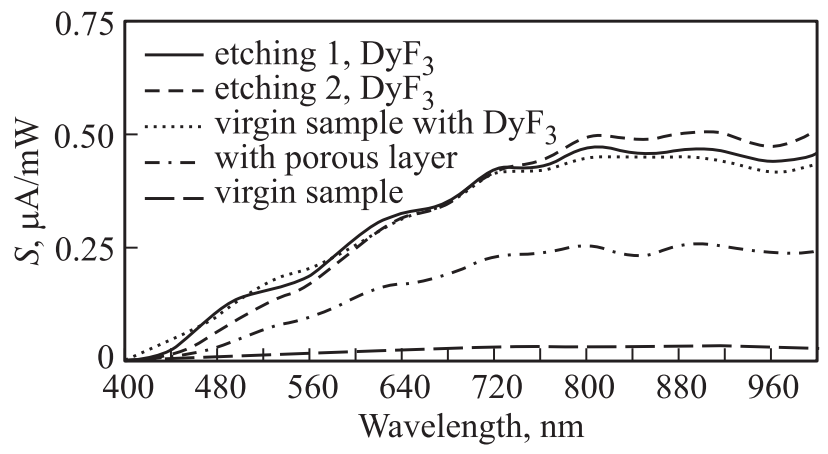

Рис. 2. Спектральные характеристики фоточувствительности образцов с пористым слоем и покрытиями $\mathrm{DyF}_{3}$.

до 0.92 мкм на разных типах рабочей поверхности образцов. В измерительную группу попали образцы с пористой поверхностью (прошедшие электрохимическое травление), образцы после диффузии лигандов и образцы, прошедшие карбидизацию. В качестве тестовых образцов использовались пластины кремния марки КДБ-3 с текстурированной или шлифованной поверхностями без пор.

\section{3. Результаты исследования}

\section{1. Фоточувствительность}

Исследование спектральных характеристик фототока показало, что нанесение покрытий из фторида диспрозия заметно увеличивает фототок практически во всем исследуемом спектральном диапазоне по сравнению с образцами без покрытия (рис. 2). Этот эффект объясняется пассивирующими свойствами пленок соединений Р3Э на травленных кремниевых поверхностях. Установлено, что нанесение пленки оксида или фторида редкоземельного элемента позволяет уменьшить спектральный коэффициент отражения от кремниевой поверхности до $0.01-1.2 \%$, увеличивает фототок более чем на $50 \%$ во всем видимом спектральном диапазоне, увеличивает время жизни неравновесных носителей заряда в 2-3 раза $[4,5]$. Из спектральных зависимостей фоточувствительности, полученных в данной работе, видно, что влияние покрытия $\mathrm{DyF}_{3}$ на пористых поверхностях не так велико, как на поверхностях без пор. Более заметно увеличение фототока в длинноволновой части спектра (800-1000 нм), что может быть связано с эффектом переизлучения (up-conversion) [6]. Этот эффект заключается в том, что при поглощении двух или более квантов с энергией, меньшей ширины запрещенной зоны кремния, в материале, содержащем ионы Р3Э (в нашем случае это фторид диспрозия), генерируется один квант с энергией, превышающей ширину запрещенной зоны кремния. Поэтому та часть длинноволнового спектра излучения, которая не поглощается в кремнии, в структурах, содержащих слои с ионами РЗЭ, преобразуется в эффективно поглощаемое в кремнии излучение, что и дает увеличение фототока в этой области спектра для таких структур.

\section{2. Фотолюминесценция}

Исследования ФЛ показали, что образцы проявляют люминесцентные свойства в двух спектральных областях - 1.17 и 1.54 мкм (рис. 3). В первом случае это -

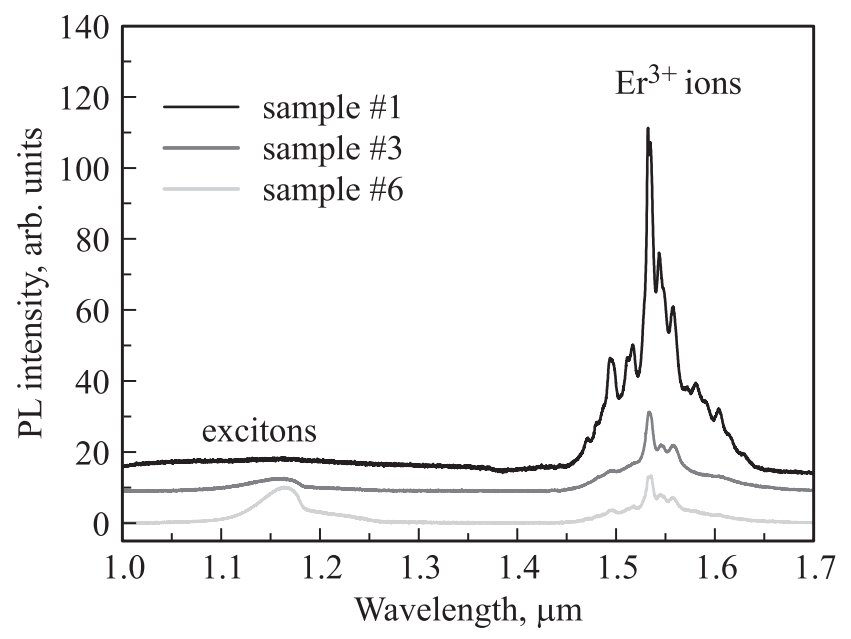

Рис. 3. Спектры фотолюминесценции (PL) образцов пористого кремния, насыщенного ионами эрбия из водного раствора азотнокислого эрбия. Приведены спектры трех образцов, полученных при разных условиях. Для наглядности спектры смещены друг относительно друга по оси ординат.

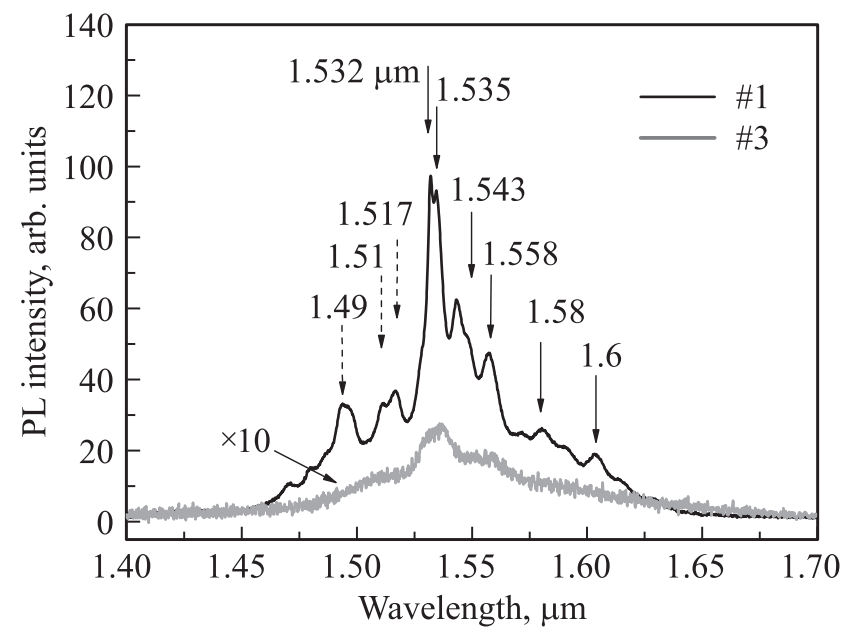

Pис. 4. Структура спектра фотолюминесценции (PL) образца пористого кремния, насыщенного ионами эрбия из водного раствора азотнокислого эрбия (образец \#1) и для сравнения неоднородно уширенный спектр образца пористого кремния, насыщенного ионами эрбия из раствора сернокислого эрбия (образец \#3). Температура измерений $300 \mathrm{~K}$. Интенсивность сигнала ФЛ последнего более чем на порядок величины меньше интенсивности сигнала ФЛ образца, полученного с пропиткой раствором азотнокислого эрбия. Стрелками отмечены линии переходов ${ }^{4} \mathrm{I}_{13 / 2} \rightarrow{ }^{4} \mathrm{I}_{15 / 2}$ иона $\mathrm{Er}^{3+}$. 
спектр экситонной ФЛ кремния, во втором - сигнал ФЛ, связанный с редкоземельной примесью эрбия. Для образцов, полученных с использованием разных пропиток (сернокислым и азотнокислым эрбием), соотношение интенсивностей сигналов эрбиевой ФЛ составляет $\sim 37$, т. е. интенсивность ФЛ при использовании азотнокислой соли эрбия значительно выше, чем сернокислой. Возможная причина этого может быть связана как с различием концентраций ионов эрбия в пропитанном слое, что объясняется разным содержанием лигандов в используемых пропитывающих растворах, так и с проблемами внедрения и активации эрбиевой примеси. Отметим, что в образце, полученном с использованием сернокислой пропитки, сигнал эрбиевой ФЛ представлен широким, неоднородно уширенным спектром, характерным для разупорядоченных материалов (рис. 4). В образцах, полученных с использованием азотнокислой пропитки, наблюдается интенсивный сигнал ФЛ (рис. 3) с характерной тонкой структурой линий, отражающей структуру расщепления мультиплета ${ }^{4} \mathrm{I}_{15 / 2}$ иона $\mathrm{Er}^{3+}$ (рис. 4). Последнее свидетельствует о внедрении редкоземельного иона в материал с выделенной структурой кристаллического поля. Заметим, что представленные на рис. 3 и 4 спектры ФЛ получены при комнатной температуре. В данном случае наблюдаемые люминесцентные особенности можно связать с внедрением редкоземельного иона в матрицу самого пористого кремния (низкоразмерные включения, ее формирующие) либо в приповерхностный слой, формируемый в процессе его пропитки. Полученные результаты требуют дополнительных исследований.

На образцах карбидизированного пористого кремния с ионами эрбия видна тенденция смещения экситонного отклика ФЛ в коротковолновую (высокоэнергетическую) область спектра, что, возможно, связано с большей шириной запрещенной зоны пористого карбида кремния по сравнению с кремнием. Однако эрбиевая люминесценция на этих образцах практически отсутствовала.

\section{3. Коэффициент зеркального отражения}

Исследование спектральных зависимостей коэффициента зеркального отражения показало, что создание пористого слоя приводит к значительному снижению коэффициента отражения как шлифованной, так и текстурированной поверхностей, особенно заметному в коротковолновой части спектра.

Величина коэффициента зеркального отражения исходного текстурированного образца не превосходит $60 \%$, а после электрохимического травления коэффициент отражения существенно снижается до $5-12 \%$ (рис. 5).

Шлифованные образцы имеют схожие зависимости: коэффициент отражения исходного образца не выше $80 \%$, а после травления он опускается до $20-25 \%$

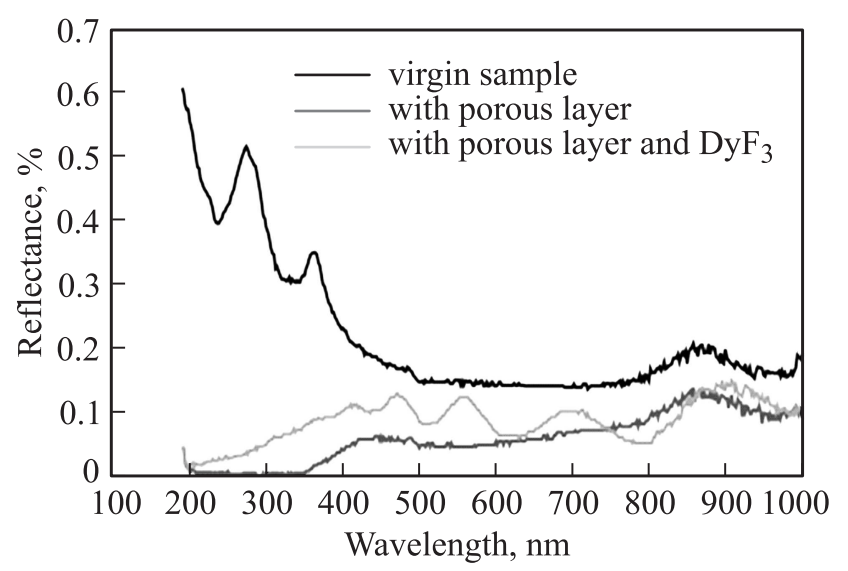

Рис. 5. Спектры отражения исходного образца (текстурированная поверхность), образца с пористым слоем (текстурированная поверхность) и образца с пористым слоем и покрытием $\mathrm{DyF}_{3}$.

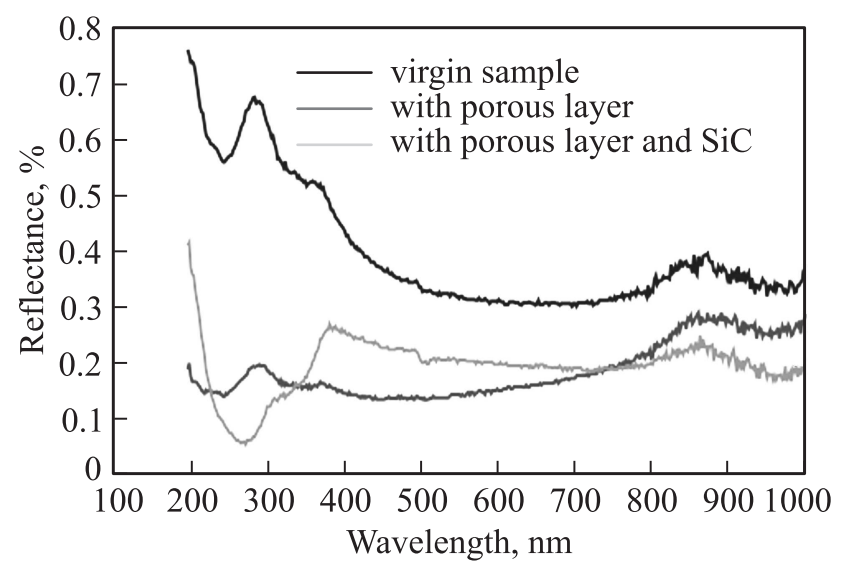

Рис. 6. Спектр отражения исходного образца, образца с пористым слоем, карбидизированного пористого образца. Во всех случаях использовалась шлифованная поверхность.

(рис. 6). После карбидизации коэффициент отражения достигает минимального значения на длине волны 250 нм и составляет $5 \%$. В длинноволновой части спектра коэффициент отражения не превышает $20 \%$.

Снижение величины коэффициента зеркального отражения для поверхности с пористым слоем может быть объяснено несколькими причинами. Это уменьшение площади отражающей поверхности из-за пористости и увеличение доли поглощенного света на пористом слое по сравнению с поверхностью без пор. Данные показывают, что показатель преломления образцов уменьшается с увеличением пористого слоя.

\section{4. Заключение}

Таким образом, проведенные исследования показывают, что каждый из компонентов многослойной структуры - пористый кремний, пористый карбид кремния, 
слой с ионами РЗЭ - оказывает положительное влияние на фоточувствительные характеристики, увеличивая эффективное поглощение энергии излучения в том или ином спектральном диапазоне, так что совместное влияние всех компонентов должно привести к расширению спектра фоточувствительности всей структуры. Однако для достижения интегрального эффекта следует изучить взаимное влияние приведенных выше компонентов, чтобы определить их оптимальные параметры: геометрию, состав, расположение в структуре.

\title{
Список литературы
}

[1] G. Conebeer, M. Green, R. Corkish, Y. Cho, E.-C. Cho, C.-W. Jiang, T. Fangsuwannarak, E. Pink, Y. Huang, T. Puzzer, T. Trupke, B. Richards, A. Shalav, K.-L. Lin. Thin Sol. Films, 511-512, 654 (2006).

[2] S.A. Sokolov, R. Rösslhuber, D.M. Zhigunov, N.V. Latukhina, V.Yu. Timoshenko. Thin Sol. Films, 562, 462 (2014).

[3] Н.В. Латухина, А.С. Рогожин, С. Саед, В.И. Чепурнов. Изв. вузов. Материалы электронной техники, № 4, 284 (2014).

[4] Ю.А. Аношин, А.И. Петров, В.А. Рожков, М.Б. Шалимова. ЖТФ, 64 (10), 118 (1994).

[5] А.И. Петров, В.А. Рожков. Письма ЖТФ, № 7, 16 (1998).

[6] A. Shalav, B. Richards, T. Trupke. Appl. Phys. Lett., 86, 013505 (2005).

Редактор Л.В. Шаронова

\section{Multilayer photosensitive structures on the basis of porous silicon and rare earth element compounds: studies of spectral characteristics}

\author{
N.Yu. Kirsanov' ${ }^{1}$, N.V. Latukhina' ${ }^{1}$ D.A. Lizunkova1, \\ G.A. Rogozhina ${ }^{1}$, M.V. Stepikhova ${ }^{2}$ \\ ${ }^{1}$ S.P. Korolyov Samara State Aerospace University \\ (National Research University), \\ 443011 Samara, Russia \\ 2 Institute for Physics of Microstructures, \\ Russian Academy of Sciences, \\ 603950 Nizhny Novgorod, Russia
}

Abstract In this work, the spectral characteristics of specular reflectance, photoluminescence (PL) and photosensitivity of the multilayer structures based on porous silicon with the rare earth (RE) ions were investigated. It is shown that the photosensitivity of such structures increases in the wavelength range between 0.4 and $1.0 \mu \mathrm{m}$, when compared with the structures without rare earth elements. The structures with $\mathrm{Er}^{3+}$ ions demonstrate luminescence response at room temperature in the spectral range of $1.1-1.7 \mu \mathrm{m}$. The photoluminescence spectrum of erbium impurity is represented by the fine line structure that reflects the splitting of ${ }^{4} \mathrm{I}_{15 / 2}$ multiplet of $\mathrm{Er}^{3+}$ ions. It is shown that the layer with a porous structure on the working surface has a significantly lower reflectance in the whole spectral range analyzed (between 0.2 and $1.0 \mu \mathrm{m}$ ). 